\title{
Mapping India's Language and Mother Tongue Diversity and its Exclusion in the Indian Census
}

\author{
Dr. Shivakumar Jolad ${ }^{1}$ and Aayush Agarwal $^{2}$ \\ ${ }^{1}$ FLAME University, Lavale, Pune, India \\ ${ }^{2}$ Centre for Social and Behavioural Change, Ashoka University, New Delhi, India
}

\begin{abstract}
In this article, we critique the process of linguistic data enumeration and classification by the Census of India. We map out inclusion and exclusion under Scheduled and non-Scheduled languages and their mother tongues and their representation in state bureaucracies, the judiciary, and education. We highlight that Census classification leads to delegitimization of 'mother tongues' that deserve the status of language and official recognition by the state. We argue that the blanket exclusion of languages and mother tongues based on numerical thresholds disregards the languages of about 18.7 million speakers in India. We compute and map the Linguistic Diversity Index of India at the national and state levels and show that the exclusion of mother tongues undermines the linguistic diversity of states. We show that the Hindi belt shows the maximum divergence in Language and Mother Tongue Diversity. We stress the need for India to officially acknowledge the linguistic diversity of states and make the Census classification and enumeration to reflect the true Linguistic diversity.
\end{abstract}

\section{Introduction}

India and the Indian subcontinent have long been known for their rich diversity in languages and cultures which had baffled travelers, invaders, and colonizers. Amir Khusru, Sufi poet and scholar of the 13th century, wrote about the diversity of languages in Northern India from Sindhi, Punjabi, and Gujarati to Telugu and Bengali (Grierson, 1903-27, vol. 1, p. 1-2). During the colonial conquest and rule of the British, India, as a nation in the European sense, based on a common culture, history, and language, did not exist. Christian missionaries, scholars, and British officials attempted to comprehend the linguistic diversity, by classifying and enumerating the Indian languages and finding their links to European and other Asian languages. Post-independence, despite the officialization of selected languages in the constitution, standardization of major languages like Hindi, Urdu, and Bengali, and linguistic reorganization based on certain dominant languages, India has remained a multicultural and multilingual country (Benedikter, 2013).

During the early colonial period, the British broadly categorized the Indian languages into vernacular languages (widely used by the common people) and the relatively more cultivated classical languages only in use among the upper and educated classes (Benedikter, 2013, p.10; Grierson, 1903-27). Owing to the power of political leverage held by languages, enumerating languages has been politically contentious with implications on legitimizing and delegitimizing linguistic identities that manifest in politics, governance, and education. Languages of the people in hilly and tribal regions which historically did not receive state patronage, have been relegated to the category of minority languages, 
although numerically they may be the dominant language in specific regions of India. These 'minority' languages are not officially recognized by the government at the national level or as regional languages in the states where people speaking these languages live in India (Groff, 2017, p. 136).

Enumerating and mapping the linguistic landscape of India is essential to understand the linguistic diversity of India and its exclusion of minority languages. Estimates of the number of languages and dialects vary from different sources depending on the type and time of the survey and its definition of language and dialect. The Linguistic Survey of India (LSI) conducted between 1894-1903 and compiled by George Grierson mapped the linguistic diversity of India for the first time. The LSI noted 179 languages and 544 dialects spoken in British India (Grierson, 1903-27).

The Census of India has been classifying and aggregating languages spoken in India since 1881. Postindependence, the Census became the official classifier of languages and 'mother tongues' and came to be used by the state for planning and administration. Owing to the complexities of extracting sociolinguistic definitions of languages and dialects, the Census avoids the term 'dialects', sticking instead with 'mother tongue'. Mother tongues are distilled from the Census' raw returns through a process of 'rationalization' which are then regrouped under languages (Census of India, 1953, p. 2). Many languages and mother tongues spoken by less than 10,000 individuals are classified as 'others', thus invisibilizing their existence.

Existing recent literature on India's linguistic landscape is largely based on Census 2001 data. The Census 2011 data on languages was released recently, in 2018. Given the rapid decadal growth in population, differential fertility rates among different socio-linguistic groups, and internal migration of people, India's linguistic profile would have undergone substantial change in the interim period.

In this article, using the most recent publicly available data on languages by Indian Census, we map the diverse linguistic landscape of India at the national and state levels. We highlight the structural problems in the classification of language, dialect, and mother Tongue, and how the Census process of rationalization delegitimizes several languages in India. We analyze languages (with their language families) and mother tongues spoken by Indians under both scheduled and non-scheduled groupings. We highlight the politics of language inclusion and exclusion in India and quantify the exclusion of language and Mother tongues for scheduled and non-scheduled languages.

We take the analysis further to a second level of quantification and ranking of the Language Diversity. We compute the aggregate measure- Linguistic Diversity Index (LDI) using Greenberg's diversity measure (Greenberg, 1956), at the national and state levels, and rank the states according to their LDI for languages and mother tongues. We trace the history of formation and bifurcation of Indian states, largely on the linguistic ground, and its impact on linguistic minorities within the states. We show high degree of language and mother tongue diversity within the Indian states and question the political patronage under "one state-one language" narrative.

The ongoing pandemic has delayed the decennial Census of India house-listing, in all likelihood pushing the Census 2021 enumeration to February 2021 which has provided extra leg space to mobilize 
reforms (Kumar, 2020). We suggest reforms to the Census enumeration and classification of languages to improve transparency, make it inclusive of all languages and reflect the true linguistic diversity of India.

\section{Language, Dialect, and Mother Tongue in India}

Counting and classifying the languages and dialects in India has been challenging for both linguists and the state agencies from colonial times to the present (Asher, 2010). An old popular Hindi saying "Kos kos par badle paani, char kos par vaani", which means, for every Kos (ancient unit of distance measurement $\sim 3 \mathrm{kms}$ ), the water changes, and for every four Kos, the language changes alluding to the linguistic diversity of India (Lobo, 2018). Two principal historical pathways which led to such linguistic diversity are: (a) Migration of population to the area from outside, and (b) the divergence within a language over time when different speakers become relatively isolated from each other and emergence of a form of speech considered as different Language (Asher, 2008, p.32).

Historical documents from the inscriptions, traveler diaries reveal that the state patronage was restricted to the either classical languages (Sanskrit, Arabic) or the "Vernacular languages" (a term Introduced by the British) of the rulers and elites. Al Baruni, the Iranian scholar who extensively traveled in India in the early 11th Century noted the near absence of Sanskrit among the common populace (Grierson, 1903-27,Vol I). Sociocultural and linguistic factors, and stratifications such as caste and religion have resulted in 'class' distinctions in language status - high, low, and popular varieties (Asher, 2008). In many North Indian states, people distinguish between Bhasha (language) and Boli (Spoken language), and list Hindi as their Language in their official documents (Groff, 2017), roughly in line with granthika, the literary variety, and vyavaharika, the colloquial variety.

Europeans from the 16 th to $18^{\text {th }}$ century had noted the general characters of principal Indian languages, and tried to compare with European languages. Systematic classification of languages and language families started in the late 18th century starting with Sanskrit by William Jones and Dravidian Languages by William Cary. The Linguistic Survey of India conducted between 1894-1903, led by Sir George Abraham Grierson, reported 179 languages and 544 dialects (Grierson, 1927; p. 18) spoken in India. The languages belonged to Aryan Languages (Indo-European), Dravidian Languages, AustroAsiatic Languages, Siamese-Chinese Languages, and Tibeto-Burman Languages. Sir Grierson compared the challenges in distinguishing a language from dialects as that of classifying 'Mountain' and 'Hills'.

Often, the distinction between language and dialect is more political than a linguistic question. The power and prestige of certain selected forms, widely used across large geographic regions, often acquire the status of a language, whereas the forms which vary regionally or used exclusively by certain lower class or caste will be relegated to the status of dialects. If mutual intelligibility is the criteria, Hindi, Urdu, and Punjabi should have been the same language, whereas Rajasthani and Kumani should be different. 
The disagreement between classification of languages and dialects leads to divergent estimates of languages in India. The People's Linguistic Survey of India (Kidwai, 2019) reported the existence of 780 languages (without making a distinction between language and dialect), the Ethnologue classifies 447 languages of India, and UNESCO has identified 197 languages in India as endangered based on the population of its speakers being less than 10,000 (UNESCO, 2009).

The Census of India acknowledged the difficulties in classifying language and dialect, and in 1951, it decided to steer clear of the controversy by adopting the approach that the "name given by the citizen to his own mother-tongue should be accepted as such and the returns with identical names totaled" (Census of India, 1953, p. 2). The Indian Census uses two specific classifications in its own unique way: 'language' and 'mother tongue'. The 'mother tongues' are grouped within each 'language'. Many 'mother tongues' so defined would be considered a language rather than a dialect by linguistic standards (Bhattacharya, 2002, p. 55). Census identifies mother tongue as the language spoken in childhood by the person's mother to the person, or in case of doubt, the language mainly spoken in the person's home/household language (Census of India, 2018). The report and data on languages and mother tongues of Census 2011 was released only in 2018 and has not been adequately analyzed in detail at the state level.

\section{Process of Rationalisation of Mother Tongues through the Census}

Census grouping of languages and mother tongues occurs through a process of rationalisation that relies on the 11 volumes of Grierson's Linguistic Survey(s) of India (1903-1927). The process of rationalization of responses, their regrouping, and consequent neglect of minority speakers leads to large scale exclusion of languages spoken by people. The 1951 Census reported the existence of at least 783 mother tongues; later Censuses reported a typically higher number of 'rationalized mother tongues' (see Table 1). Census 2011 reported 19,569 raw returns, which were rationalized into 1,369 mother tongues, which were regrouped into 270 mother tongues (spoken by more than 10,000 people) and 121 languages. Languages spoken by 1.87 million people and mother tongues of 18.6 million people are placed under 'other' category (Census of India, 2018). Thus, the Census's process of enumeration does not "represent the full linguistic diversity of India; in fact, it minimises it" (Kidwai, 2019).

\begin{tabular}{|l|l|l|l|}
\hline Year & $\begin{array}{l}\text { Returned mother } \\
\text { tongues }\end{array}$ & $\begin{array}{l}\text { Rationalized } \\
\text { mother tongues }\end{array}$ & $\begin{array}{l}\text { Legitimized } \\
\text { Languages }\end{array}$ \\
\hline 1951 & $\sim$ & 783 & $\sim$ \\
\hline 1961 & $\sim 3,000$ & 1,652 & 193 \\
\hline 1971 & $\sim 3,000$ & $\sim$ & 104 \\
\hline 1981 & $\sim$ & $\sim$ & $\sim$ \\
\hline 1991 & $\sim 10,000$ & 1,576 & 114 \\
\hline 2001 & 6,661 & 1,635 & 122 \\
\hline 2011 & 19,569 & 1,369 & 121 \\
\hline
\end{tabular}


Table 1: Counting Languages in the Indian Census (Source: Groff, 2017, Census of India, 2001, and Census of India, 2018)

Census 2011 lists 121 languages with 22 Scheduled and 99 non-scheduled languages spoken by more than 10,000 people. About 270 mother tongues have been rationalized and regrouped under these languages. The languages belong to Indo-European (Indo-Aryan, Germanic (English), Iranian (Persian, Afghani)), Dravidian, Austo-Asiatic, and Tibeto Burmese language families. These, along with Semito-Hamitic (Arabic), constitute the main languages. The most diverse language group is the Tibeto-Burmese group with 66 languages. The most spoken languages belong to Indo-Aryan branch with $78 \%$ of population, Dravidian $20 \%$, Austro-Asiatic languages $1.1 \%$, and Tibeto-Burmese just $1 \%$, spoken in North-Eastern India (see Table 2).

\section{Language Family and Speakers in India- 2011}

Census 2011: Langauge Family of Scheduled and Non-Scheduled Languages

\begin{tabular}{|c|c|c|c|c|c|}
\hline SI no & $\begin{array}{l}\text { Language } \\
\text { Family }\end{array}$ & Sub family & $\begin{array}{l}\text { Number of } \\
\text { Languages }\end{array}$ & $\begin{array}{r}\text { Number of } \\
\text { speakers }\end{array}$ & $\begin{array}{l}\text { Percentage of } \\
\text { Speakers }\end{array}$ \\
\hline \multirow[t]{3}{*}{1} & Indo-European & Indo-Aryan & 21 & $945,052,555$ & $78.05 \%$ \\
\hline & & Iranian & 1 & 21,677 & $0 \%$ \\
\hline & & Germanic & 1 & 259,678 & $0.02 \%$ \\
\hline 2 & Dravidian & & 17 & $237,840,116$ & $19.64 \%$ \\
\hline 3 & Austro-Asiatic & & 14 & $13,493,080$ & $1.11 \%$ \\
\hline 4 & Tibeto-Burmese & & 66 & $12,257,382$ & $1.01 \%$ \\
\hline 5 & Semito-Hamitic & & 1 & 54,947 & $0 \%$ \\
\hline
\end{tabular}

Table: Shivakumar Jolad * Source: Census 2011 * Get the data * Created with Datawrapper

Table 2: Language Family and Speakers in India. Source: Census 2011 language tables (Census of India, 2018). The $0 \%$ percent entries in percentage of speakers occur due to rounding off to 2 decimal places.

\section{Inclusion and Exclusion under Scheduled Languages}

The Constituent Assembly, during 1948-49, debated the 'officialization' of certain languages over others based on their scripts, number of speakers, rights of linguistic minorities, and media of instruction (Constituent Assembly Debates, 1946-49; Agnihotri, 2007). The eighth schedule under the Constitution of India recognizes 22 official languages; the rest of the languages (non-scheduled) and mother tongues which are spoken by 39.7 million people according to Census 2011 are treated as 'minority' languages (Constitution of India, 2008, Schedule VIII). Some of these 'minoritized' languages have speakers exceeding 3 million, surpassing the population of a few European countries. Census figures and the Constitutional provisions under the eighth schedule have acted as an instrument of legitimization and delegitimization of languages in India by governments at both, the central and 
state levels. The use and planning of official languages have immediate implications on the education opportunities in schools and colleges (Groff, 2017). Majoritarian language imposition by the state and the markets limits the access to resources and upward mobility for the disadvantaged linguistic minorities.

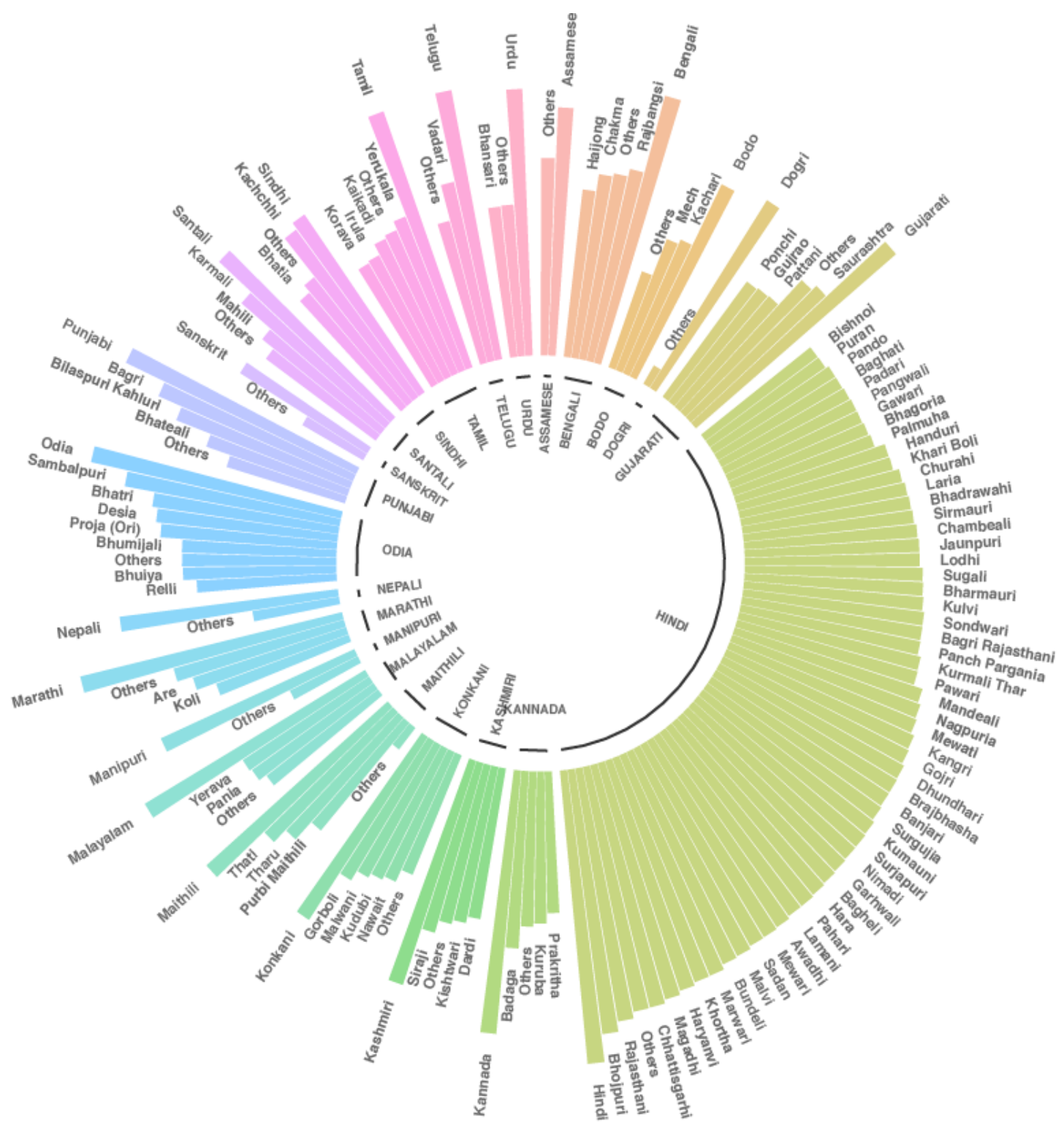

Figure 1: Scheduled Languages and their mother tongues in India. Source: Census 2011 language tables.

Scheduled Languages meant the Government was obligated to take measures for the development of those languages so that "they grow rapidly in richness and become effective means of communicating modern knowledge" (Benedikter, 2013). The official language resolution of 1968 states that "concerted measures should be taken for the full development of scheduled languages in the interest of the educational and cultural advancement of the country" (Ministry of Home Affairs, GOI, 1968). These languages are promoted by the state and are well-represented in Indian state bureaucracies, the judiciary, markets, and in schools, as media of instruction. 
In 1950, there were 14 languages under 8th Schedule: Assamese, Bengali, Gujarati, Hindi, Kannada, Kashmiri, Malayalam, Marathi, Oriya, Punjabi, Sanskrit, Tamil, Telugu, and Urdu. Further constitutional amendments added languages like Sindhi (in 1967), 71st Amendment added Nepali, Manipuri, and Konkani (1992), and 92nd constitutional amendment added Maithili, Dogri, Santali, and Bodo in 2004, taking total scheduled languages to 22 (Benedikter, 2013, p. 16). Scheduled Languages are born primarily through political considerations. Sanskrit is in the official Schedule even though only 24,821 people claim it as their language, whereas Bhili with 10.4 million speakers and Gondi with 2.98 million speakers are excluded (Census 2011 figures). There is a demand for 38 languages to be included in the 8th schedule (Ministry of Home Affairs, GOI, n.d.). Only Sanatali from the Austro-Asiatic family and Bodo and Manipuri (Maitei) from the Tibeto-Burmese Family are in the Scheduled Languages list.

\section{Different Mother Tongues under Hindi language}

\begin{tabular}{ll} 
Census 2011- India & \\
& Population \\
Bhojpuri & $50,579,447$ \\
Rajasthani & $25,806,344$ \\
Chhattisgarhi & $16,245,190$ \\
\hline Magadhi/Magahi & $12,706,825$ \\
\hline Haryanvi & $9,806,519$ \\
\hline Khortha/Khotta & $8,038,735$ \\
\hline Marwari & $7,831,749$ \\
\hline Bundeli/Bundel khandi & $5,626,356$ \\
\hline Malvi & $5,212,617$
\end{tabular}

Figure 2: Top nine Mother tongues listed under Hindi with more than million speakers. Source: Census 2011.

While scheduled languages receive official recognition, their mother tongues do not. Many of the 123 mother tongues identified under the Schedule have more than 5 million speakers and yet are not given the status of language (see Figure 1). Bhojpuri has 50.6 million speakers, (more than Spanish speakers in Spain; Polish in Poland; Dutch in the Netherlands), Rajasthani (25.8 million), Chhattisgarhi (16.2 million), and Magadhi (12.7 million) have more than 10 million speakers and still do not have the language tag (see Figure 2). Apart from these, over 16.7 million people speak mother tongues of Hindi classified under 'other', derecognizing their linguistic identity. 


\section{Mother Tongues under Odia language}

(excluding the main language)

\begin{tabular}{l|c|} 
Sambalpuri & $2,630,381$ \\
\hline Bhatri & 334,258 \\
\hline Desia & 227,313 \\
\hline Proja (Ori) & 156,354 \\
Bhumijali & 34,651 \\
\hline Bhuiya/Bhuyan[Ori] & 32,126 \\
\hline Relli & 12,969
\end{tabular}

Figure 3: Mother tongues of Odia language (excluding the main language). Source: Census 2011.

Delegitimization of Non-scheduled Languages and Mother tongues

Non-Scheduled Languages in India (Top 25)

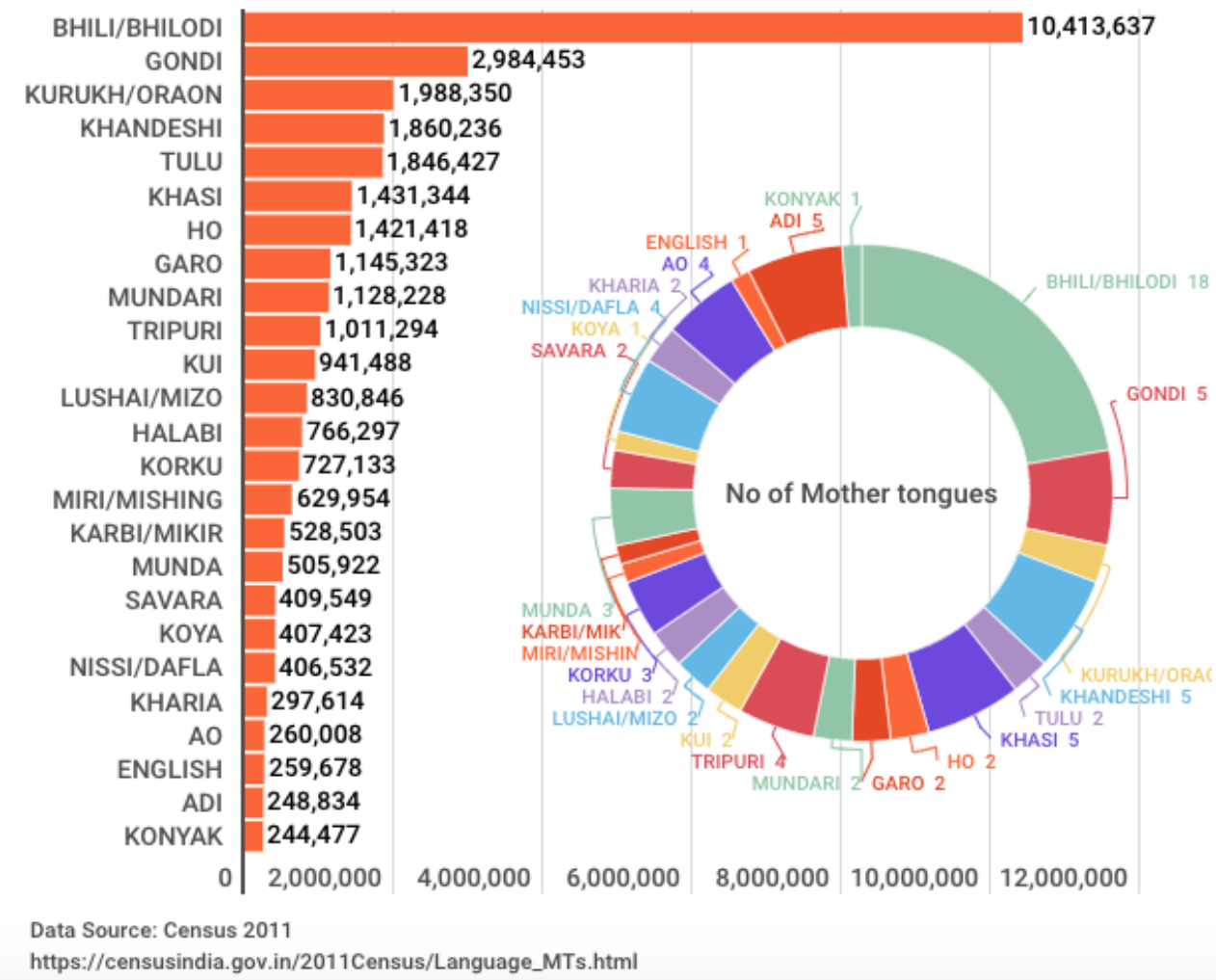

Figure 4: Top 25 Non-Scheduled Languages and the number of mother tongues associated with them. Source: Census 2011.

Census 2011 lists 99 non-scheduled languages (which includes English) and 147 mother tongues (part B) spoken by more than 10,000 people. Some of the non-scheduled languages have 3-6 million speakers - more than certain European national languages. The largest of these being Bhili/Bhilodi with 10.4 million native speakers, Gondi (3 million), Kurukh (2 million), and Khandeshi with 1.86 
million speakers (see Figure 4). The exclusion of these languages have implications for the land and forest rights of the Adivasis and other minority groups. Barring Santali, Manipuri (Maitei), and Bodo, all the languages belonging to the Auto-Asiatic and Tibeto-Burmese Family spoken by the tribal belt, the North-East, and Himalayan states in India are given the non-scheduled language status.

\section{Speakers of AUSTRO-ASIATIC LANGUAGES}

Percentage of people speaking Austro-Asiatic language family

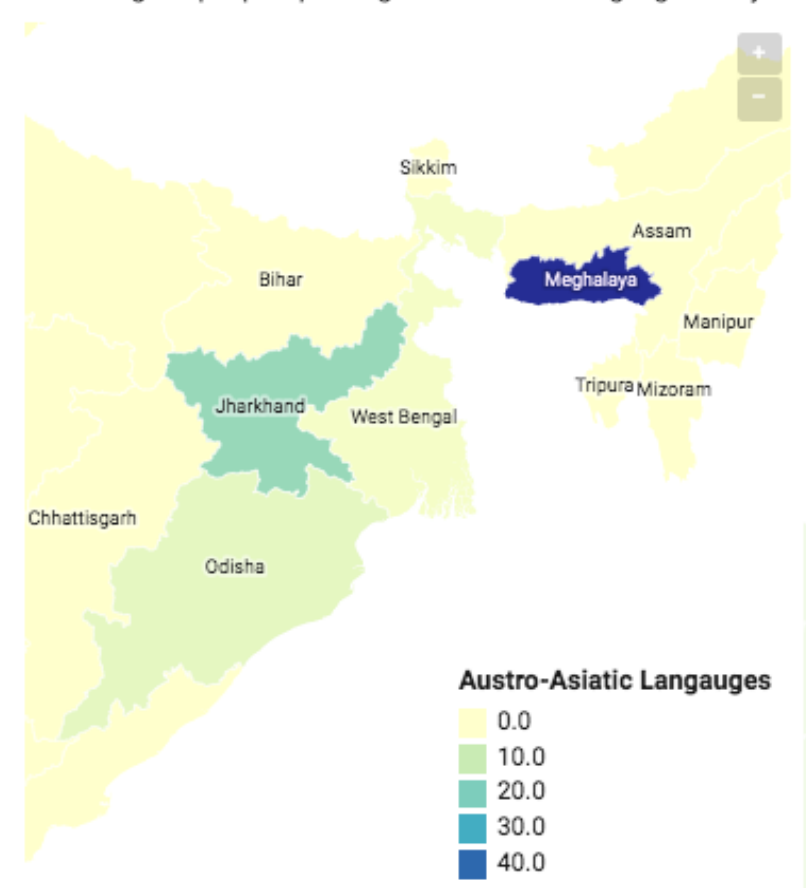

\section{Speakers of TIBETO-BURMESE}

Percentage of people speaking TIBETO-BURMESE language family

TIBETO-BURMESE Langauges

0.0

20.0

40.0

60.0

80.0

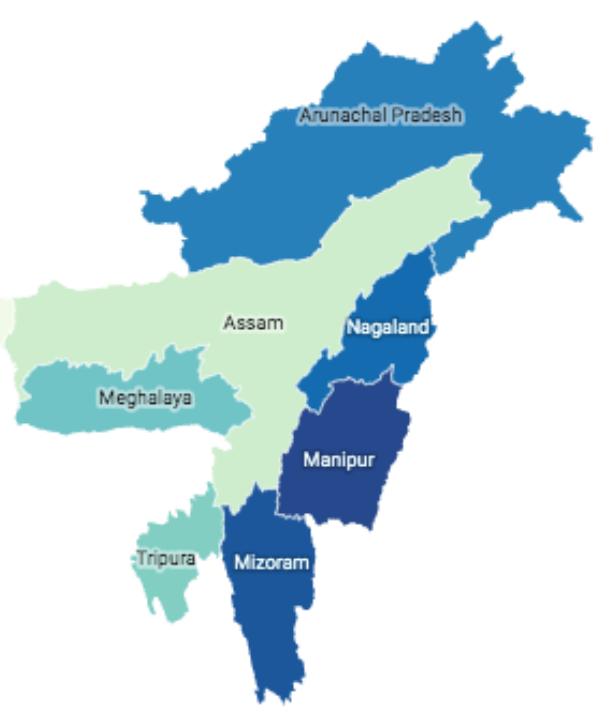

Figure 5: Geographical distribution of (a) Austro-Asiatic and (b) Tibeto-Burmese Languages in India. Source: Census 2011.

\section{Excluded languages and Mother Tongues}

Census classification arguably leads to large-scale exclusion of languages. It lists only those languages and mother tongues that are spoken by more than 10,000 people. Census 2011 excluded the languages of 1.87 million people (by placing them under the 'other' category). The cumulative population excluded for speaking 'other' minority mother tongues is 18.6 million, of which Hindi alone has 16.7 million people. Figure 7 shows the mother-tongues excluded under the 'other' category within their main Language. Assamese has 495,000 speakers, Bengali 284,000, Gujarati 163,000, and Marathi 158,000 speakers listed under 'other' mother tongues. 


\section{Population (in 000) speaking 'other' category of Mother Tongue}

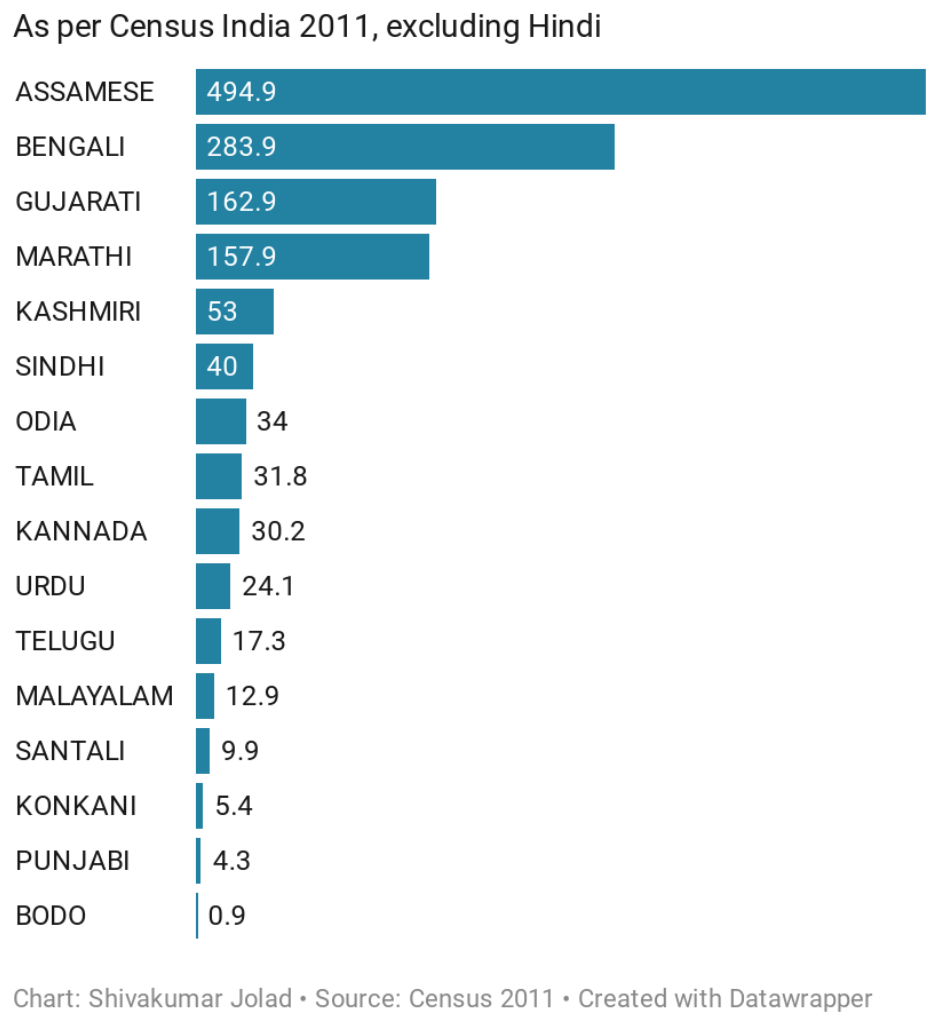

Figure 7: Population placed under 'other' category of mother tongue from their main language (excluding Hindi's others, which includes 16.7 million speakers). Source: Census 2011.

\section{Language of the States and the State of Linguistic Minorities}

Given India's current political status quo, majoritarian parties support the notion of 'One Nation, One Language', i.e., Hindi, for use across India, administrative and otherwise (Telegraph, Sept 2019). This notion promotes monolingualism, rather than valuing multilingualism and multilingual practice (Groff, 2017). As with any other issue that involves groups with vested interests, the issue of deciding upon lingua franca of Indian Union and its states has attracted controversy ever since Independence. Article 345 of the Indian Constitution gives the states the autonomy to choose any language used in their territory (or Hindi and English) and thus legitimize the official language at the state-level. Postindependence, India had three types of states, almost all of which were multilingual. The Part A states represented former governors provinces of British India, Part B represented princely states, and Part $\mathrm{C}$ represented former chief commissioners' provinces and some princely states. The States Reorganisation Commission (SRC) was constituted in 1953 to examine the approach and feasibility of linguistic reorganization of states in India. The SRC recommended use of regional language of the state for political and administrative work, while simultaneously promoting the use of one language to "ensure real consciousness of identity and interests between government and the people" (Sengupta, 2009 , p. 159). State reorganization on the basis of majority languages led to more pronounced linguistic homogeneity (Benedickter, 2013). 
Following the State Reorganization Act, 1956, new states were carved out in three broad phases: first, between 1956 and 1970, central and southern Indian states were reorganized according to linguistic majorities in a complicated and conflicted manner. The Congress, dominated by north-Indian politicians (from Hindi-speaking states), was pitted against the Dravidian South. Andhra Pradesh, Gujarat, Kerala, Maharashtra, Haryana, Karnataka, among others, were carved out of other states during this phase. The Partition of Bombay created two states-Maharashtra (dominated by Marathi speakers) and Gujarat (Gujarati). From 1972-87, six North-Eastern states were created (and Sikkim joined the Indian Union in 1975) due to various ethinic movements and have remained some of the linguistically diverse states in India. In 1966, Punjab was divided into the Punjabi-speaking 'PunjabSuba' and Hindi-speaking Haryana (Devulapalli, 2019). Where several minority languages coexisted within a geographic area, a request for separate statehood was sometimes first denied, and only later conceded. Examples of this are evident post-2000, with the creation of Jharkhand and Telangana.

The linguistic reorganization of states based on the State Reorganization Committee's (1953) recommendations led to fears about suppression of rights of linguistic minorities. While newer states of India have adopted non-scheduled languages as their official language, like Kokborok in Tripura, Mizo in Mizoram, Khasi, Garo and Jaintia in Meghalaya and French in Pondicherry, the linguistic reorganization succeeded in bringing majority of the scheduled languages, a "home", under state umbrella (Rajendra, 1997, p.81). Although SRC seeks to secure "political and economic justice" to linguistic groups, the language in question is the dominant language of the state, and not the diverse set of languages spoken within the state. The SRC set criteria for classifying states into monolingual ( $70 \%$ of the population speaks the same language), bilingual (30\% or more speak a language other than the language of the region), criteria for the use of dominant language of the district if the latter is different from the state's official language (if $70 \%$ or more of the population of the district speaks it), and bilingual printing of government documents (Benedickter, 2013, p. 22). In spite of this, the states continue to promote their politically-dominant languages in political and administrative affairs, largely ignoring linguistic minorities.

Article 30(1) of the Constitution provides the right to establish and administer educational institutions of their choice, and the state will not be discriminating against it while granting aid. The seventh amendment to the Constitution added Article 350A with a directive for states and local authorities to provide adequate facilities for instruction in the mother-tongue at the primary stage of education to children belonging to linguistic minority groups. However, even after 60 years of the amendment, languages of linguistic minorities in states continue to be underrepresented as Medium of Instruction (MOI) in schools. An analysis of DISE (District Information System of Education, 2015-16) reveals that only 28 languages are used as the main medium of instruction in schools throughout the nation (see MOI-1 in Figure 8). Most of the non-scheduled languages spoken by millions of people are not used as a medium of instruction in Indian schools. Out of 1.52 million schools, only 1,352 schools use a language distinct from the 28 languages as the main MOI. While a few non-scheduled languages of the North-East, Bodo, Garo, Mizo, Bhutia, Lepcha, and Limboo do find representation as MOI in schools, many tribal and minority languages are used only as preparatory or para-medium of instruction in primary schools (Khubchandani, 1997). 


\section{India Medium of Instruction and Languages taught}

\begin{tabular}{|c|c|c|c|c|}
\hline MOI1 & L-MOI2 L-MOI3 & L-MOl4 & & \\
\hline & MOI1 & L-MOI2 & L-MOI3 & L-MOI4 \\
\hline Hindi & 743,200 & 285,260 & 275,951 & 276,389 \\
\hline English & 149,185 & 75,721 & 12,201 & 4,184 \\
\hline Other & 1,352 & 39,938 & 48,468 & 49,832 \\
\hline Bengali & 104,452 & 2,697 & 2,112 & 1,824 \\
\hline Marathi & 90,203 & 3,182 & 2,329 & 2,263 \\
\hline Telugu & 78,818 & 1,295 & 58 & 10 \\
\hline Oriya & 68,351 & 3,890 & 3,273 & 3,138 \\
\hline Kannada & 62,284 & 1,182 & 481 & 431 \\
\hline Assamese & 53,367 & 540 & 175 & 154 \\
\hline Gujarati & 48,786 & 525 & 490 & 460 \\
\hline Tamil & 45,735 & 612 & 42 & 21 \\
\hline Urdu & 22,741 & 6,192 & 1,225 & 783 \\
\hline Punjabi & 24,021 & 938 & 441 & 180 \\
\hline Malayalam & 12,440 & 770 & 534 & 273 \\
\hline Sanskrit & 557 & 5,643 & 3,351 & 803 \\
\hline Khasi & 4,555 & 1,215 & 14 & 5 \\
\hline Bodo & 3,071 & 1,840 & 25 & 25 \\
\hline Garo & 3,595 & 290 & 27 & 1 \\
\hline Mizo & 1,685 & 21 & 2 & 0 \\
\hline Nepali & 747 & 741 & 63 & 17 \\
\hline Manipuri & 581 & 434 & 197 & 9 \\
\hline Konkani & 77 & 17 & 4 & 2 \\
\hline Bhutia & 38 & 29 & 14 & 6 \\
\hline Sindhi & 32 & 5 & 5 & 4 \\
\hline French & 0 & 13 & 19 & 8 \\
\hline Lepcha & 1 & 3 & 5 & 10 \\
\hline Limboo & 0 & 2 & 13 & 4 \\
\hline Kashmiri & 1 & 6 & 4 & 4 \\
\hline Dogri & 1 & 1 & 1 & 5 \\
\hline
\end{tabular}

Figure 8: Medium of Instruction in Indian schools. Source: DISE 2015-16.

\section{Linguistic Diversity Index}

In spite of all its limitations of exclusion of languages and mother tongues, the Census gives an opportunity to measure and map the linguistic diversity (LD) of India and its states. The exclusion by Census discussed earlier is likely to give lower estimates of LD than its ground reality. The Greenberg Diversity Index is widely used to measure Linguistic Diversity (Greenberg, 1956). The Greenberg's 
Linguistic Diversity Index (LDI) based on the fraction of population speaking different languages, defined as:

$$
L D I=1-\sum_{i=1}^{n}\left(\frac{P_{i}}{P}\right)^{2}
$$

Where $P_{i}$ is the population-speaking language $i$ and $P$ is the total population of the Nation or State, and $\mathrm{n}$ is the number of languages. The $\mathrm{LDI}=0$ when every person in the union under consideration speaks the same language. Maximum diversity of $\mathrm{LDI}=(1-(1 / \mathrm{n}))$ is achieved when everyone has an equal number of speakers. LDI will increase and approach 1 , as the number of languages increases (and approaches practical infinity) and speakers are spread uniformly across the languages. We have computed India's linguistic diversity at both the national and state levels, at two hierarchical levels provided by the Census 2011-language and mother tongue. We also split the diversity into Scheduled Language and Non-scheduled Language diversity.

\section{Method for Computation}

The approach involves splitting Census 2011 the language tables (477 entries) into Main Languages (including the 'others'; $121+1)$ and Mother Tongues $(270+86$ 'others' +1 'other' language). Further, each of these divisions can be split into scheduled and non-scheduled branches. The LDI is calculated based on equation 1 for each of these categories. The results of LDI calculations are shown in Fig. 9 and 10.

The LDI of India, considering the restrictive 121 language classification of Census 2011, amounts to 0.78 . The mother tongue diversity is 0.9 , which is closer to the diversity index of 0.93 calculated by UNESCO using Ethnologue's catalogue of 425 languages (UNESCO, 2009). The slight difference might be due to the inclusion of more number of languages, for instance, the 197 endangered languages spoken by less than 10,000 people, in the UNESCO list (see also: The Economist, 2012). The LDI for mother tongues is higher because the population of speakers is distributed over a larger set. 


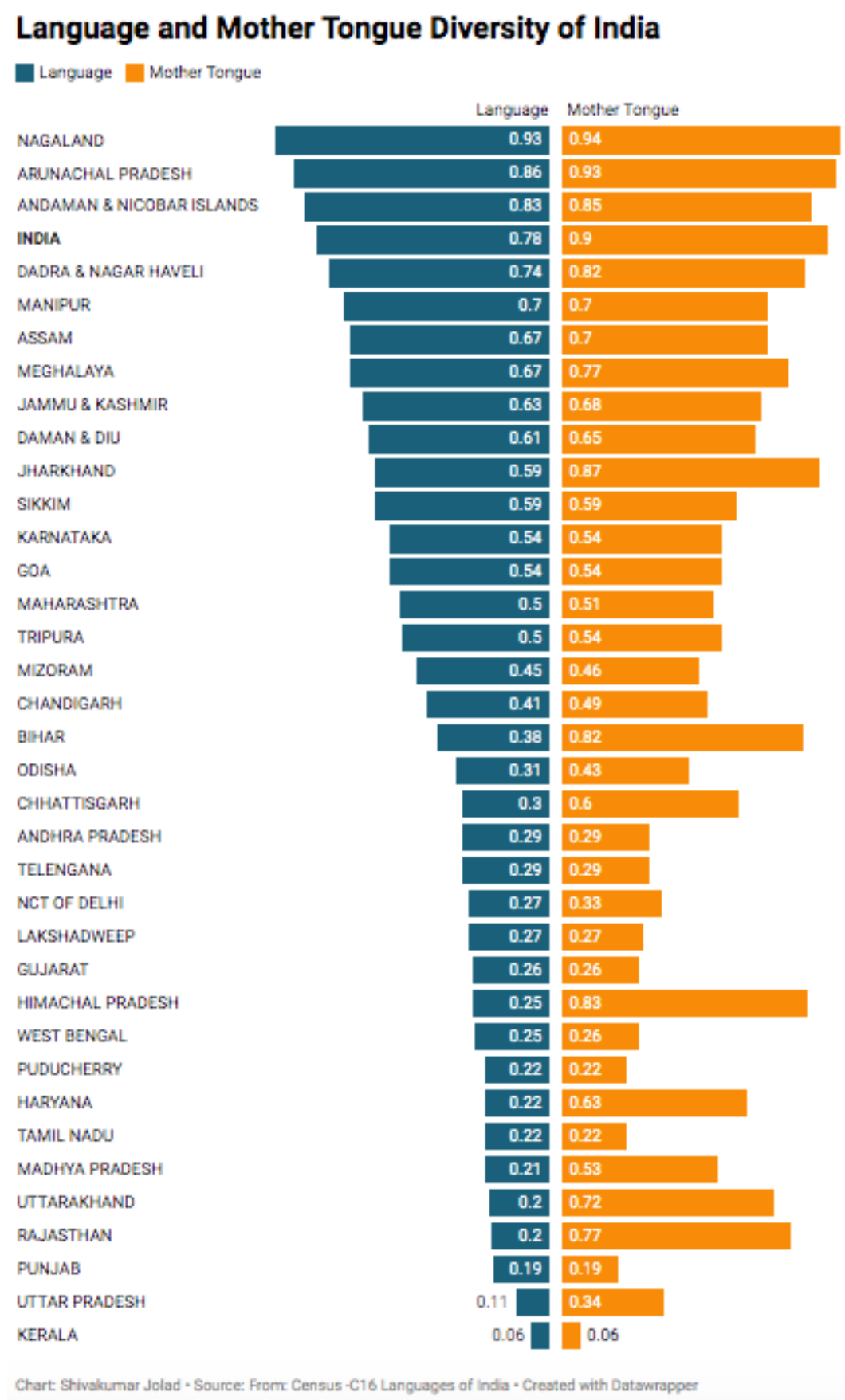

Figure 9: Linguistic Diversity of Indian states (left) LDI-Languages (right) LDI-Mother Tongue, computed using state level data from Indian Census 2011 language tables.

\section{Linguistic Diversity of States in India}

Figure 9 shows the LDI of Indian states by Language and Mother Tongue. A Choropleth map of the Language Diversity Index can be seen in Figure 10. The most linguistically diverse states are the North-Eastern states, followed by tribal areas and islands like Andaman and Nicobar. Small states with distinct ethnic and tribal groups show greater linguistic diversity than large states like Uttar Pradesh. Isolated communities develop their own languages; hilly and tribal states have much greater diversity 
than the plains and plateaus. Forces of homogenization by the state do not penetrate deeply into these regions.

\section{Linguistic Diversity of India}

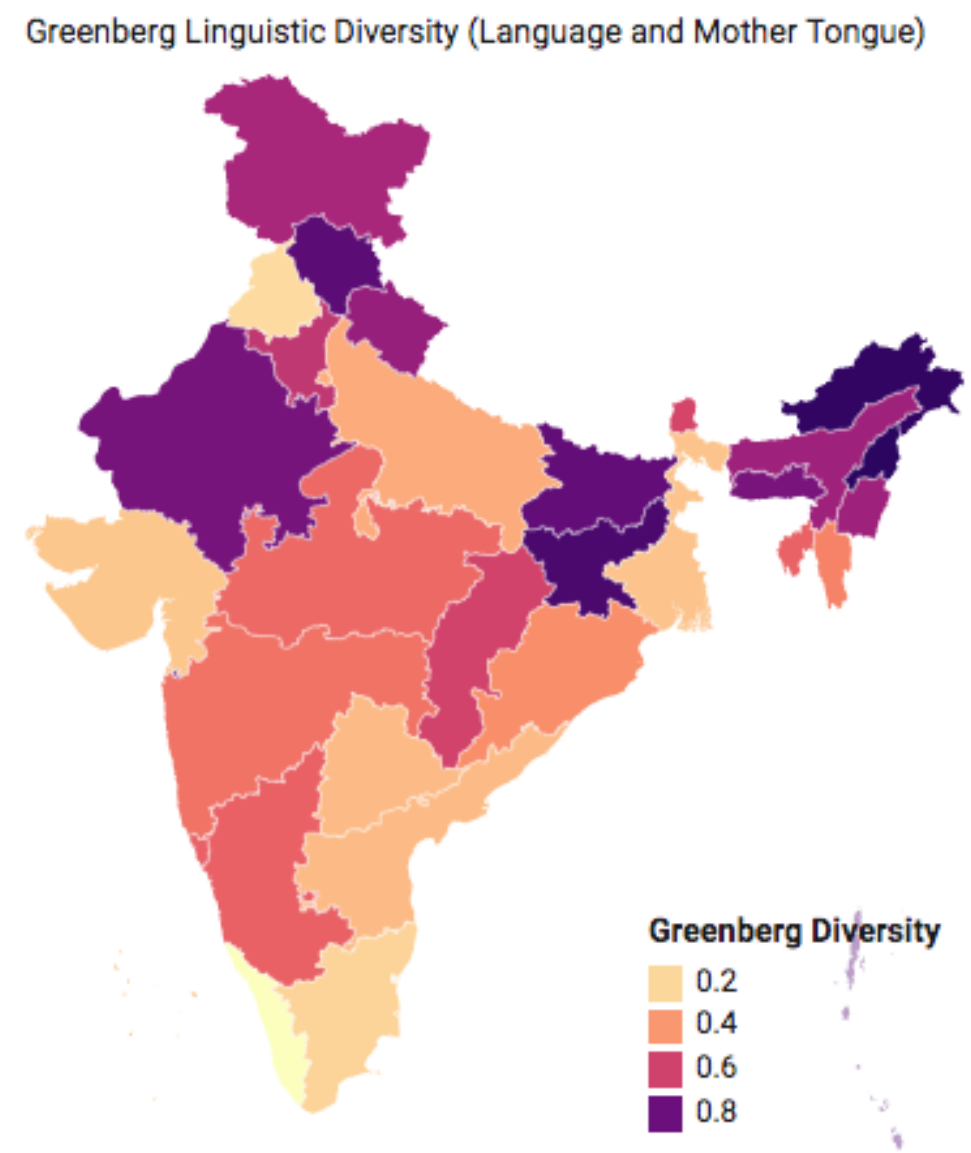

121 Scheduled and Non-Scheduled Languages and Mother Tongues

Map: Shivakumar Jolad · Source: Census $2011 \mathrm{C} 16$ series · Get the data *

Created with Datawrapper

Figure 10: Map of Linguistic Diversity of Indian states Languages and Mother Tongue, computed using state level data from Indian Census 2011 language tables.

\section{Most Diverse States}

The North-Eastern states of Nagaland and Arunachal Pradesh have LDI-MT higher than 0.9 (see Figure 11). Similarly, Manipur, Assam and Meghalaya higher LDI-MT is greater than 0.7. The languages spoken in these states largely belong to Tibeto-Burmese family, except Meghalaya (AstrtoAsiatic and Tibeto Burmese) and Assam (Indo-Aryan), Sikkim (Indo-Aryan and Tibeto-Burmese), and Tripura (Indo-Aryan and Tibeto-Burmese). Anadaman and Nicobar Islands have a mixture of IndoAryan (Bengali), Dravidian (Tamil, Telugu), and Astro-Asiatic Languages (Nicobarese). 


\section{NAGALAND- Languages spoken by the people}

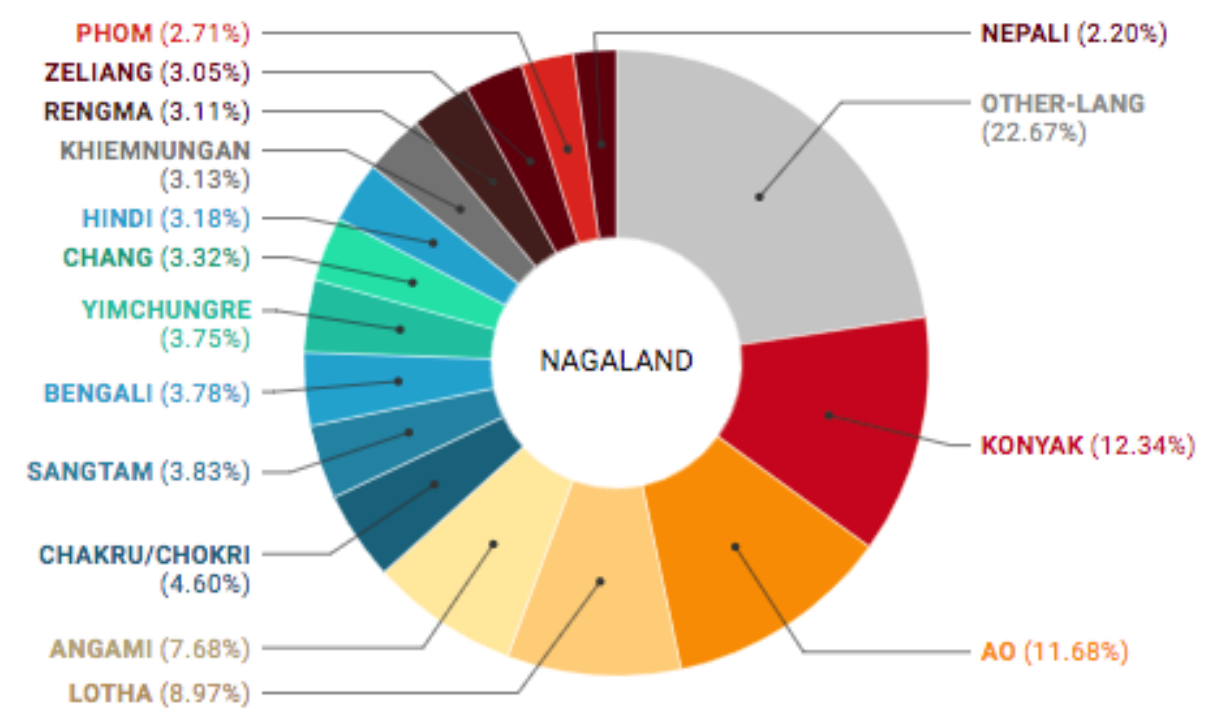

Chart: Shivakumar Jolad + Source: Census 2011 + Get the data + Created with Datawrapper

\section{Arunachal Pradesh- Languages spoken by the people}

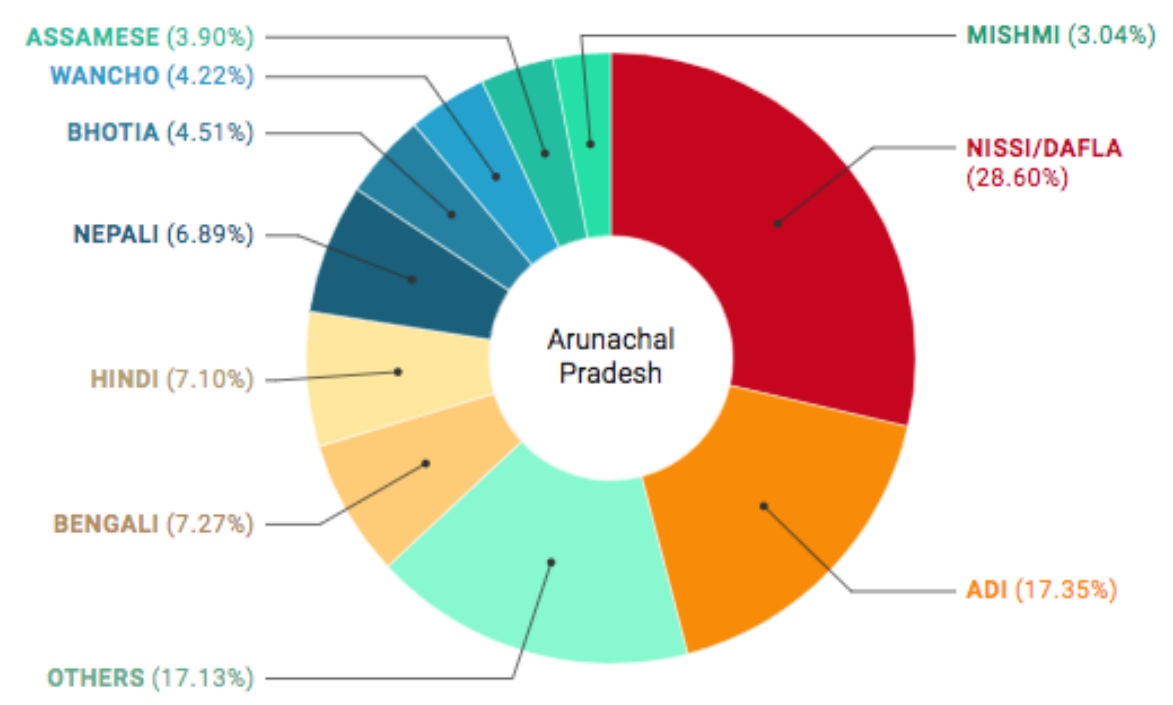

Chart: Shivakumar Jolad - Source: Census 2011 - Get the data * Created with Datawrapper

Figure 11: Languages spoken by two of the most linguistically diverse states in Indian (top) Nagaland (bottom) Arunachal Pradesh 


\section{Linguistically most diverse (small) states in India}

Language, Percentage of Speakers, and Language Diversity Index

\begin{tabular}{|c|c|c|c|c|c|c|c|}
\hline LANGUAGE & NAGALAND & LANGUAGE & $\begin{array}{l}\text { ARUNACHAL } \\
\text { PRADESH }\end{array}$ & LANGUAGE & $\begin{array}{l}\text { ANDAMAN } \\
\text { \& NICOBAR } \\
\text { ISLANDS }\end{array}$ & LANGUAGE & $\begin{array}{r}\text { DADRA } \\
\& \\
\text { NAGAR } \\
\text { HAVELI }\end{array}$ \\
\hline KONYAK & $12.34 \%$ & NISSI/DAFLA & $28.60 \%$ & BENGALI & $28.49 \%$ & BHILI/BHILODI & $37.26 \%$ \\
\hline $\mathrm{AO}$ & $11.68 \%$ & ADI & $17.35 \%$ & HINDI & $19.29 \%$ & HINDI & $26.16 \%$ \\
\hline LOTHA & $8.97 \%$ & BENGALI & $7.27 \%$ & TAMIL & $15.20 \%$ & GUJARATI & $21.48 \%$ \\
\hline ANGAMI & $7.68 \%$ & HINDI & $7.10 \%$ & TELUGU & $13.24 \%$ & MARATHI & $7.01 \%$ \\
\hline CHAKRU/CHOKRI & $4.60 \%$ & NEPALI & $6.89 \%$ & NICOBARESE & $7.60 \%$ & KONKANI & $2.26 \%$ \\
\hline SANGTAM & $3.83 \%$ & BHOTIA & $4.51 \%$ & MALAYALAM & $7.22 \%$ & ORIYA & $1.30 \%$ \\
\hline BENGALI & $3.78 \%$ & WANCHO & $4.22 \%$ & KURUKH/ORAON & $3.96 \%$ & BENGALI & $0.91 \%$ \\
\hline YIMCHUNGRE & $3.75 \%$ & ASSAMESE & $3.90 \%$ & KHARIA & $1.07 \%$ & MAITHILI & $0.64 \%$ \\
\hline CHANG & $3.32 \%$ & MISHMI & $3.04 \%$ & MUNDA & $1.00 \%$ & MALAYALAM & $0.63 \%$ \\
\hline Other-Lang & $40.06 \%$ & OTHERS & $17.13 \%$ & Other-Lang & $2.94 \%$ & Other-Lang & $2.36 \%$ \\
\hline $\begin{array}{l}\text { Linguistic } \\
\text { Diversity Index }\end{array}$ & 0.93 & & 0.86 & & 0.83 & & 0.74 \\
\hline
\end{tabular}

Table: Shivakumar Jolad • Source: Census $2011 \cdot$ Created with Datawrapper

Table 3: Languages spoken in top three linguistically most diverse small states in India

\section{Linguistically most diverse (large) states in India}

Language, Percentage of Speakers, and Language Diversity Index

\begin{tabular}{|c|c|c|c|c|c|c|c|}
\hline LANGUAGE & ASSAM & LANGUAGE & $\begin{array}{l}\text { JAMMU \& } \\
\text { KASHMIR }\end{array}$ & LANGUAGE & JHARKHAND & LANGUAGE & KARNATAKA \\
\hline ASSAMESE & $48.38 \%$ & KASHMIRI & $53.27 \%$ & HINDI & $61.95 \%$ & KANNADA & $66.54 \%$ \\
\hline BENGALI & $28.92 \%$ & HINDI & $20.83 \%$ & SANTALI & $9.91 \%$ & URDU & $10.83 \%$ \\
\hline HINDI & $6.73 \%$ & DOGRI & $20.04 \%$ & BENGALI & $9.74 \%$ & TELUGu & $5.84 \%$ \\
\hline BODO (S) & $4.54 \%$ & PUNJABI & $1.75 \%$ & URDU & $5.96 \%$ & TAMIL & $3.45 \%$ \\
\hline MIRI/MISHING & $1.98 \%$ & BHOTIA & $0.86 \%$ & $\mathrm{HO}$ & $3.01 \%$ & MARATHI & $3.38 \%$ \\
\hline NEPALI & $1.91 \%$ & TIBETAN & $0.80 \%$ & KURUKH/ORAON & $2.89 \%$ & HINDI & $3.30 \%$ \\
\hline KARBI/MIKIR & $1.64 \%$ & KHANDESHI & $0.28 \%$ & MUNDARI & $2.86 \%$ & TULU & $2.61 \%$ \\
\hline ORIYA & $0.70 \%$ & SHINA & $0.26 \%$ & ORIYA & $1.61 \%$ & KONKANI & $1.29 \%$ \\
\hline SANTALI & $0.68 \%$ & MARATHI & $0.18 \%$ & MALTO & $0.46 \%$ & MALAYALAM & $1.27 \%$ \\
\hline GARO & $0.55 \%$ & NEPALI & $0.18 \%$ & KHARIA & $0.42 \%$ & GUJARATI & $0.19 \%$ \\
\hline OTHER-LANG & $3.96 \%$ & OTHER-LANG & $1.55 \%$ & OTHER-LANG & $1.19 \%$ & OTHER-LANG & $1.19 \%$ \\
\hline $\begin{array}{l}\text { Language } \\
\text { Diversity Index }\end{array}$ & 0.67 & & 0.63 & & 0.59 & & 0.54 \\
\hline
\end{tabular}

Table: Shivakumar Jolad - Source: Census 2011 - Created with Datawrapper

Table 4: Languages spoken in top three linguistically most diverse large states in India 


\section{Least Diverse States}

Among the least diverse states are Kerala, Uttar Pradesh, Punjab, and Rajasthan. In Kerala, 97\% of the population speak one language-Malayalam (32.4 million speakers). Pania, one of the MT of Malayalam, is spoken by only 15,530 speakers in Kerala. The LDI and LDI-MT are roughly the same0.06. Uttar Pradesh (UP), the largest state of India with a population of about 200 million according to Census 2011 (larger than Brazil, the fourth largest country in the world), has Hindi as the dominant language- $-94.08 \%$, and next Urdu at 5.42 percent, the remaining languages falling within half a percent point.
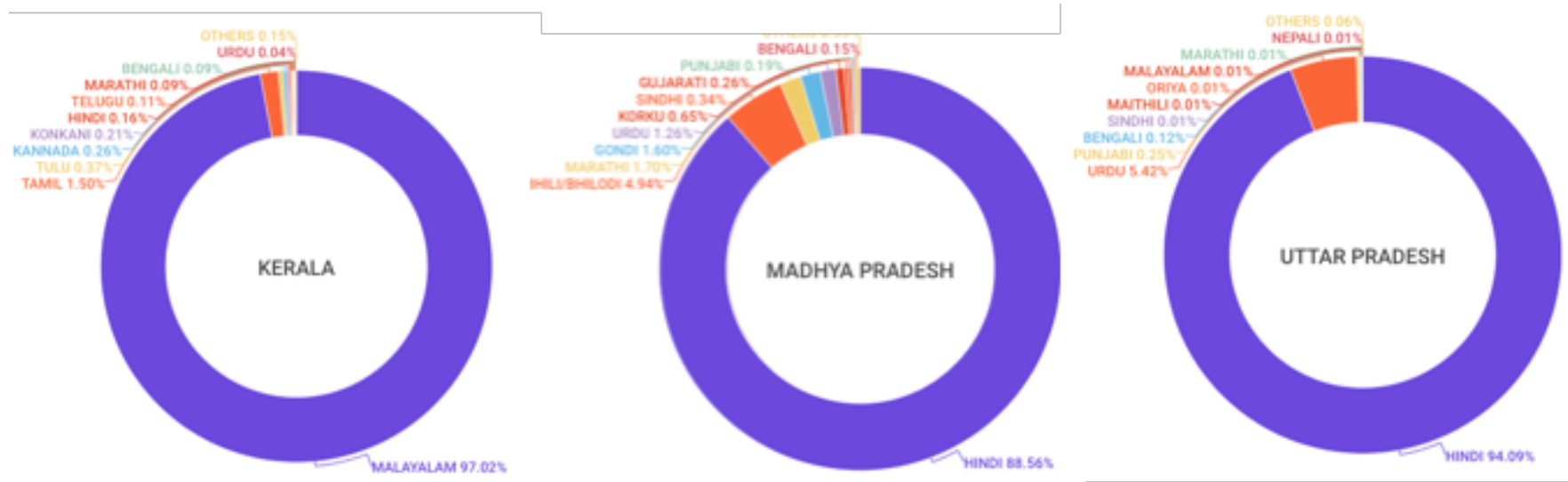

Figure 12: Linguistically least diverse major states in India

\section{Language versus Mother Tongue Diversity in States}

Many states which show lower language diversity according to Census classification show high mother tongue diversity. This is especially true in Hindi-speaking states in North, Central, and Western India, as many mother-tongues have been grouped under Hindi. The LDI of Hindi-speaking states are low primarily because 54 languages are treated as mother tongue under Hindi. Of the top 10 states ranked according to the difference between Language and Mother Tongue Diversity, 9 have Hindi as the official state language. For Himachal Pradesh, Rajasthan, and Uttarakhand, the difference between LDI-Mother Tongue and LDI-Language are more than 0.5 (.579, 0.575, 0.514 respectively, see Table 5). The top 9 states which show the greatest difference between Mother Tongue and Language Diversity are the states which have Hindi as the official language of the state. The standardized Hindi is primarily the Khariboli dialect of Delhi and neighbouring areas of Northern India, and its universal adoption by these states undermines the Linguistic Diversity of the region. 


\begin{tabular}{|c|cccc|}
\hline \multicolumn{5}{|c|}{$\begin{array}{l}\text { Difference between Language and Mother Tongue diversity of Indian States } \\
\text { (Greenberg Linguistic Diversity Index) }\end{array}$} \\
\hline S. No. & State & Language & Mother Tongue & Difference \\
\hline 1 & HIMACHAL PRADESH & 0.254 & 0.833 & 0.579 \\
2 & RAJASTHAN & 0.197 & 0.772 & 0.575 \\
3 & UTTARAKHAND & 0.202 & 0.716 & 0.514 \\
4 & BIHAR & 0.376 & 0.818 & 0.442 \\
5 & HARYANA & 0.216 & 0.625 & 0.409 \\
6 & MADHYA PRADESH & 0.212 & 0.527 & 0.315 \\
7 & CHHATTISGARH & 0.296 & 0.597 & 0.301 \\
8 & JHARKHAND & 0.59 & 0.87 & 0.280 \\
9 & UTTAR PRADESH & 0.112 & 0.342 & 0.230 \\
10 & ODISHA & 0.313 & 0.43 & 0.117 \\
\hline & INDIA & $\mathbf{0 . 7 8 3}$ & $\mathbf{0 . 9}$ & 0.117 \\
\hline
\end{tabular}

Table 5: Difference between Language and Mother Tongue diversity of Indian States

\section{Linguistic Diversity of India: Language and Mother Tongue}

Greenberg's Linguistic Diversity
NAGALAND
ARUNACHAL PRADESH
INDIA
JHARKHAND
ANDAMAN \& NICOBAR ISLANDS
HIMACHAL PRADESH
DADRA \& NAGAR HAVELI
BIHAR
RAJASTHAN
MEGHALAYA
UTTARAKHAND

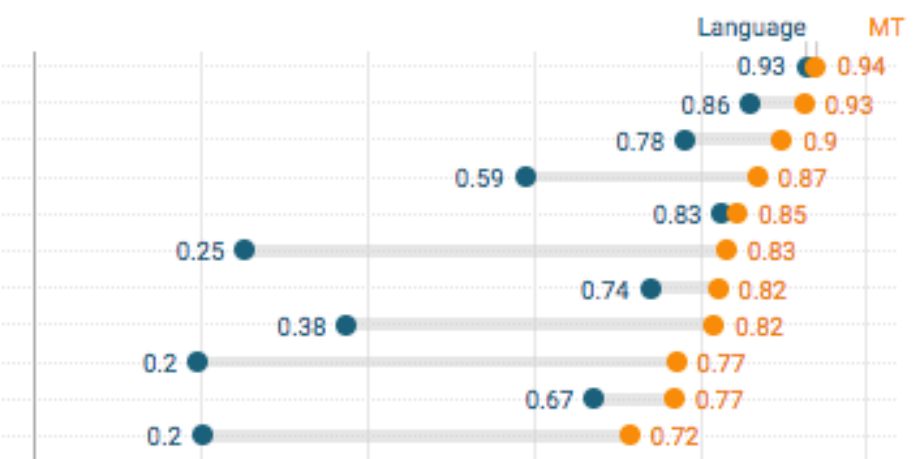

Figure 13: Separating Diversity of Language and Mother Tongue

In Himachal Pradesh (HP), Hindi as spoken language is $85.89 \%$, but Hindi as mother tongue $(15,68 \%)$ comes the third after Pahari (31.9\%) and Kangri (16.25\%). Both these languages are clubbed under Hindi, along with Mandeali, Kulvi, Bharmouri/Gaddi, Chambeali/Chameli, and Sirmauri, among others. Punjabi, Nepali, Kashmiri, and Dogri are other languages spoken. In Rajasthan, the LDIMother Tongue of Rajasthan (0.772) is four times higher than LDI-Language (0.197). The language diversity appears low as nearly $90 \%$ of the population are listed as speakers of Hindi, whereas only $27.31 \%$ identify it as their mother tongue. About 36.84\% identify Rajasthani as their mother tongue. Other major mother tongues are Marwari (9.04\%), Mewari (6.09\%), and Wagadi (4.94\%). Uttar 
Pradesh's (UP) LDI-MT (0.34) is three times larger than LDI-Language (0.112). UP has a significant proportion of mother tongues of Hindi: Bhojpuri (10.8\%), Awadhi (1.9\%), Bundeli/Bundelkhandi $(0.65 \%)$, and Brajbhasha $(0.36 \%)$, among others.
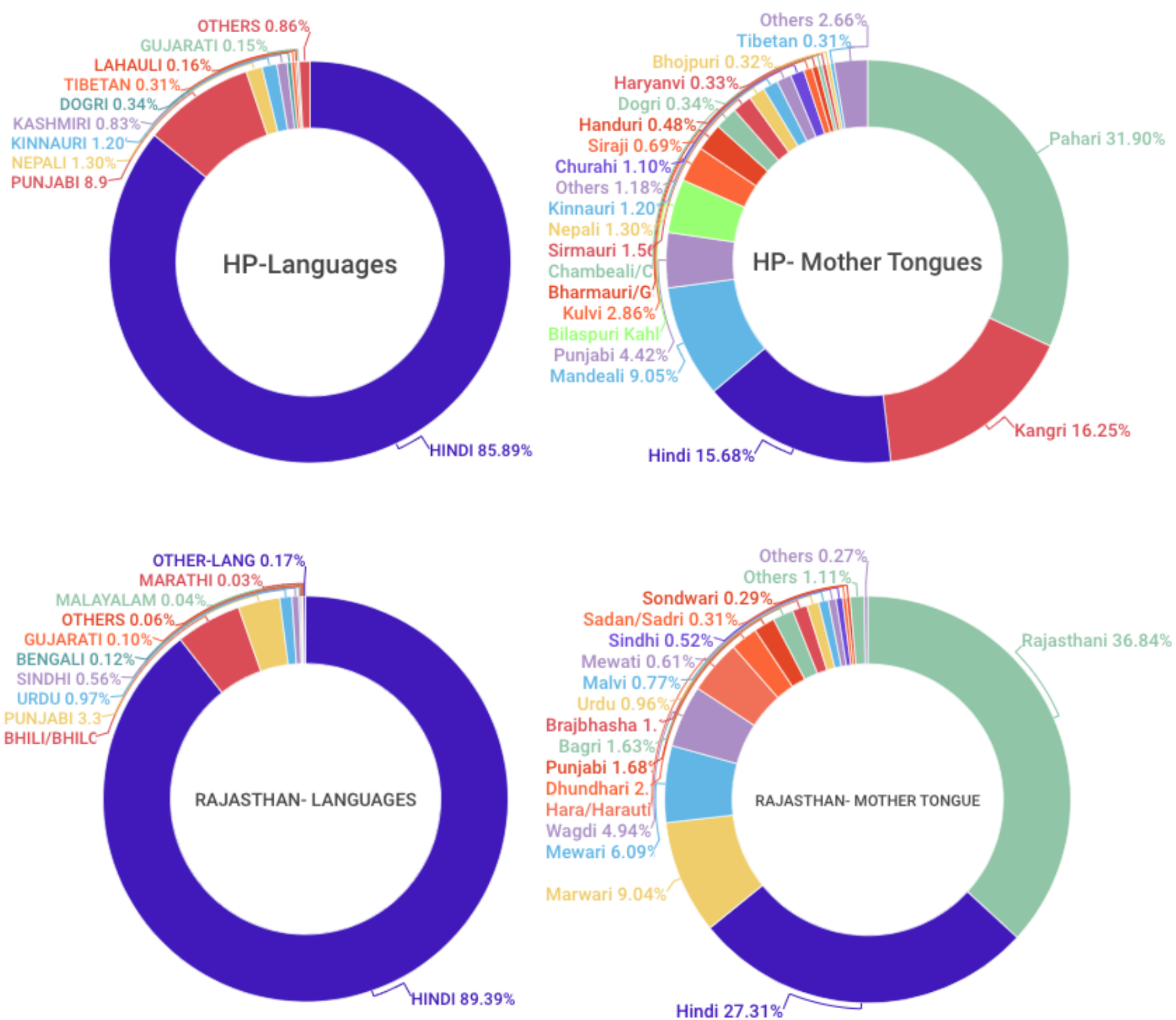

Figure 14: Illustrating difference between Language and Mother Tongue Diversity of two large "Hindi speaking" speaking states.

The two examples above show how the Census classification hides the linguistic diversity of states and promotes homogeneity of official languages. All the top nine states listed above use Hindi as official state language, and it also happens to be widely used in schools as a medium of instruction, and for administrative use. Languages such as Pharai, Kangri, Rajastani, Marwari, and Mewari are among hundreds of other languages widely spoken by the people that find no administrative recognition. 


\section{Conclusion}

Language classification and officialization has been contentious since the time of Independence in India. Disregarding the enormous linguistic diversity, the nation and the states have used selective languages as political tools for identity and homenegiation. The Constitution of India paved the way for official promotion of a few selected languages listed in the 8th Schedule while neglecting hundreds of other languages and dialects spoken in India. The linguistic reorganization of states paved the way for the use of the dominant language of the state as the official language, neglecting diversity of speakers within the states, rendering many to the 'linguistic minority' category. The creation of new states between 1956 and the present gave political legitimacy to few selected languages through their official use in these states.

The Census of India is the official aggregator and classifier of languages in India (although its process of enumeration and classification has delegitimized the linguistic identity of millions of Indians speaking minority or minoritized languages). In this article, using Census 2011 data, we have computed the Linguistic Diversity of India (LDI) and Indian states at two levels of classificationlanguage and mother tongue. We have shown that if only main languages are considered, the LDI of India is 0.78 , which falls well below the computed value by UNESCO at 0.93 . However, the mother tongue LDI of 0.90 is much closer to the latter. This still does not factor in the languages and mother tongues cumulatively spoken by 20.47 million people as the Census places them under an 'Others' category. North-Eastern India, hilly regions, and tribal states in Central India have the highest LDI, where the languages mostly belong to Tibeto-Burman and Austo-Asiatic Languages. Some of the large Hindi-speaking states in North, Western, and Central India like Uttar Pradesh, Rajasthan, Uttarakhand, and Madhya Pradesh are at the bottom in LDI-Language ranking, but that is largely because Hindi camouflages numerous (54) mother tongues within itself. 9 out of 10 states which show maximum divergence between LDI-MT and LDI-Language are the states with Hindi as their official language for administration and medium of instruction in government schools. In North and Central India, Hindi is used as the official language, even though the mother tongues used by people significantly differ from Hindi (HP, Rajasthan, Jhakhand, Bihar, Chhattisgarh).

The Census has played a key role in strengthening majoritarian languages and languages with significant political clout while neglecting the vast majority of languages spoken by the linguistic minorities and scheduled tribes in the central and Himalayan states. The process of rationalization of mother tongues erases their linguistic identity and delegitimizes minority languages at multiple levels: (a) it erases the identity of languages spoken by millions of people by not publishing it in official records, (b) it homogenizes the linguistic identity of mother tongues by placing them under the umbrella of dominant languages, and (c) it derecognizes languages and mother tongues spoken by less than the threshold of 10,000 people by placing them under the 'Others' category. Census enumeration, instead of representing linguistic diversity, minimizes it.

The Indian Census 2021 is being delayed due to the COVID-19 pandemic. This frees up time to debate upon and address the question of capturing language information and its subsequent aggregation and classification in India. The Census should give legitimacy to the linguistic identities of all Indian 
residents. The upcoming Census should disclose the classification of languages and mother tongues, including those spoken by less than 10,000 people. The states should acknowledge the linguistic diversity they hold within them, recognize the linguistic rights of minorities, and as far as possible be inclusive of all the major languages spoken in its official use and educational institutions. The states should move away from policies of language imposition and promote a diverse set of languages in official communication and schools, books, and print media.

\section{References}

1. Agnihotri, R. K. (2007). Identity and multilinguality: The case of India. In A. B. M. Tsui \& J.W. Tollefson (Eds.), Language policy, culture and identity in Asian contexts (pp. 185-204). Mahwah, NJ: Lawrence Erlbaum.

2. Asher, R. E. (2010). Language in Historical Context, in Kachru, B. B., Kachru, Y., \& Sridhar, S. N. (Eds.). (2008). Language in South Asia. Cambridge University Press, 32.

3. Benedikter, T. (2013). Minority languages in India: An appraisal of the linguistic rights of minorities in India. Asien: Forschung und Wissenschaft/LIT Studies on Asia.

4. Bhattacharya, S.S, (2002), Languages in India - Their Status and Function, in: Itagi/Singh (eds.), Linguistic Landscape in India, CIIL Mysore.

5. Census of India (1953), Paper No.6, Languages - 1951 Census; Retrieved from : http://1si.gov.in:8081/jspui/bitstream/123456789/775/1/23902 1951_LA.pdf

6. Census of India (2001), General note on languages, retrieved from: https://www.censusindia.gov.in/Census_Data_2001/Census_Data_Online/Language/gen_not e.html

7. Census of India (2018), Paper 1 of 2018- 2011 Census, Retrieved from https://censusindia.gov.in/2011Census/Language MTs.html

8. Constituent Assembly Debates (1946-49)., Retrieved December 11, 2020, from https://www.constitutionofindia.net/constitution assembly debates

9. Constitution of India (2008), Retrieved from: https://www.india.gov.in/mygovernment/constitution-india/constitution-india-full-text

10. Devulapalli, S. (14 Aug, 2019). How India's map has evolved since 1947. Mint. https://www.livemint.com/news/india/how-india-s-map-has-evolved-since-19471565803882094.html 
11. Eberhard, D. M., Simons, G. F., \& Fennig, C. D. (Eds.). (2019). Ethnologue: Languages of Asia. SIL International.

12.Groff, C. (2017). Language and language-in-education planning in multilingual India: a minoritized language perspective. Language Policy, 16(2), 135-164.

13. Greenberg, J. H. (1956). The measurement of linguistic diversity. Language, 32(1), 109-115.

14. Grierson, G. A. (1903-1927). Linguistic Survey of India (Vol. 1, Part 1: Introductory). Calcutta: Government of India.

15. Kidwai, A. (2019). The People's Linguistic Survey of India Volumes: Neither Linguistics, Nor a Successor to Grierson's LSI, but still a Point of Reference. Social Change, 49(1), 154159.

16. Khubchandani, L. M. (1997). Language policy and education in the Indian subcontinent. In Encyclopedia of language and education (pp. 179-187). Springer, Dordrecht.

17. Kumar, V. (2020, 13 Aug). Census 2021 will be delayed. It gives Modi govt time to bring long-pending reforms. The Print. https://tinyurl.com/Kumar-Print-2020

18. Lobo, B. (2018, 15 Jul). Losing Our Language. Church of St. Andrew, Bandra. Retrieved December 5, 2020, from https://standrewchurch.in/losing-our-language/

19. Ministry of Home Affairs, GOI. (1968), The official language resolution, 1968 ,Department of official language, Ministry of Home Affairs, Retrieved from: https://rajbhasha.gov.in/en/official-language-resolution-1968

20. Ministry of Home Affairs, GOI. (n.d), Constitutional provisions relating to Eighth Schedule https://www.mha.gov.in/sites/default/files/EighthSchedule_19052017.pdf

21. Rajendra, P. (1997). Minorities in India--Protection and Welfare., APH Pub. Corp., New Delhi

22. Sengupta, P. (2009). Linguistic diversity and economic disparity: An issue for multiculturalism in India. The International Journal of Diversity in Organisations, Communities and Nations, 9(1).

23. Telegraph. (2019, Sept). One nation, One language: Why is Amit Shah inviting trouble? Telegraph. Retrieved November 23, 2020, from https://www.telegraphindia.com/opinion/one-nation-one-language-why-is-amit-shah-invitingtrouble/cid/1705428 
24. The Economist. (2012, February 15), Speaking in tongues. The Economist https://www.economist.com/graphic-detail/2012/02/15/speaking-in-tongues

25. UNESCO. (2009). Investing in cultural diversity and intercultural dialogue: UNESCO world report. UNESCO. 